Article

\title{
Association between Body Fat Percentage and Physical Performance in Male Korean Police Officers
}

\author{
Jooyoung Kim ${ }^{1}\left(\mathbb{D}\right.$, Wi-Young So ${ }^{2, *,+} \mathbb{C}$ and Sangwoon Kim ${ }^{3, *,+}$ \\ 1 Office of Academic Affairs, Konkuk University, Chungju-si 27478, Korea; hirase1125@hanmail.net \\ 2 Sports and Health Care Major, College of Humanities and Arts, Korea National University of Transportation, \\ Chungju-si 27469, Korea \\ 3 Department of Police Administration, College of Social Science, Daegu Catholic University, \\ Gyeongsan-si 38430, Korea \\ * Correspondence: wowso@ut.ac.kr (W.-Y.S.); podori48@cu.ac.kr (S.K.) \\ + Contributed equally to this work.
}

Received: 19 April 2020; Accepted: 5 May 2020; Published: 9 May 2020

check for updates

\begin{abstract}
Body composition can affect a police officer's physical performance. We analyzed the correlation between body fat percentage (\%fat) and physical performance in 326 male Korean police officers (age, $44.2 \pm 9.2$ years; height, $174.0 \pm 4.5 \mathrm{~cm}$; weight, $76.4 \pm 8.8 \mathrm{~kg}$ ) who were classified into two groups according to their \%fat: high-fat (HFG, \%fat $\geq 25 \% ; n=135)$ and low-fat (LFG, \%fat $<25 \%$; $\mathrm{n}=191$ ). Physical performance tests included a 100-m sprint, push-ups, sit-ups, and a hand-grip strength test. The results showed significant differences in performance between the groups in the 100 -m sprint $(p=0.001)$ and in the sit-up test $(p=0.033)$, but not for push-ups $(p=0.130)$ or hand-grip strength $(p=0.255)$. A significant positive correlation was found between \%fat and the 100-m sprint $(\mathrm{r}=0.255, p<0.000)$, and a negative correlation was found between \%fat and push-ups $(\mathrm{r}=-0.117$, $p=0.035)$ and sit-ups $(\mathrm{r}=-0.199, p<0.000)$. However, there was no significant correlation between $\%$ fat and hand-grip strength $(\mathrm{r}=-0.093, p=0.095)$. To improve physical performance, an intervention training program is recommended for reducing \%fat, because high levels of \%fat in male Korean police officers were associated with low levels of physical performance.
\end{abstract}

Keywords: body fat; muscle strength; physical performance; police officer

\section{Introduction}

Police officers are under high levels of physical and psychological stress because of their wide-ranging duties in terms of crime prevention and safety maintenance [1,2]. Therefore, managing and maintaining components of their health, including physical fitness, is important to maintain efficient performance of police officers' duties and to reduce the risk of injury [3]. Police officers are more likely to have poor body composition because their jobs entail many sedentary hours with little physical activity and exercise, resulting in irregular sleep and eating habits [4]. In connection with this, several studies have reported increases in the numbers of overweight and obese police officers [5-7]. Their physical performance levels decreased significantly as job experience increased [8,9]. Alghamdi et al. [5] reported 66.9\% of police officers in Riyadh, Saudi Arabia, had been diagnosed as overweight or obese, and Vancini et al. [7] reported that a group of police officers with a high body mass index (BMI) showed high psychological index scores for anxiety and depression. Lagestad et al. [8] reported that the performance of bench presses and standing long jumps by police officers who had worked for 16 years decreased approximately between $10 \%$ and $32 \%$ based on past police academy graduation times, and the effects were evident in terms of reduced upper body strength. Sörensen et al. followed up the physical performance of Finnish police officers who had worked for 15 years, in terms 
of maximal oxygen consumption, push-ups, sit-ups, and pull-ups, and found that their performance with respect to these items had significantly decreased from baseline data [9].

Another study reported a significant negative correlation between police officers' body fat percentages (\%fat) and their physical performance, measured according to activities such as bench presses, sit-ups, and push-ups [10]. Moreover, one study found a positive relationship between a \%fat and the time taken to perform a $2.4-\mathrm{km}$ run, and this was inversely related to performance in terms of push-ups, sit-ups, and the distance of sit-and-reach tests [11]. One recent study reported that police officers' reaction times were positively correlated to body fat [12]. Taken together, these previous findings suggest that police officers' \%fat can significantly affect their physical performance. However, these three previous studies involved only American or Brazilian police officers [10-12], and there were differences in terms of physical performance tests, methods of \%fat measurement, and types of running races undertaken. Police officers who participated in a study by Dominski et al. were from special operation coordination units, whose job duties and body composition status were different from those of the general police force [12]. To the best of our knowledge, there have been no studies conducted on the relationship between \%fat and physical performance in male Korean police officers. Therefore, we aimed to investigate the correlation between \%fat and physical performance in male Korean police officers.

\section{Materials and Methods}

\subsection{Participants}

We included 326 male police officers (average age, $44.2 \pm 9.2$ years; height, $174.0 \pm 4.5 \mathrm{~cm}$; weight, $76.4 \pm 8.8 \mathrm{~kg}$ ) working at Daegu Dongbu police station, located in Daegu-si, Gyeongsangbuk-do, Republic of Korea in 2019. The exclusion criteria were as follows: (1) chronic health-related problems, (2) history of cardiovascular, respiratory, musculoskeletal, or metabolic disease, (3) psychological problems; (4) smoking; and (5) drug intake during the previous 3 months. The study design was approved by the Institutional Review Board (number: 2020-0017) at Daegu Catholic University, Daegu, Republic of Korea after reviewing all content. The study's purpose and procedures were specifically explained to the participants, all of whom voluntarily signed informed consent forms. The participants were classified into a high \%fat group (HFG, $n=135$ ) and a low \%fat group (LFG, $n=191$ ) depending on their measured \%fat. In this study, the criteria used to classify \%fat were based on those used in a previous study in a Korean population [13]. Participants were classified into the HFG if their \%fat was $>25 \%$ and into the LFG if their \%fat was $<25 \%$. Participant characteristics for each group are presented in Table 1.

Table 1. The characteristics of the participants in each group.

\begin{tabular}{|c|c|c|c|}
\hline Variables & $\begin{array}{l}\text { High \%Fat Group } \\
\quad(\mathrm{HFG}, \mathrm{n}=135)\end{array}$ & $\begin{array}{l}\text { Low \%Fat Group } \\
\quad(L F G, n=191)\end{array}$ & $p$ \\
\hline Age (years) & $45.0 \pm 8.9$ & $43.5 \pm 9.3$ & 0.149 \\
\hline Height (cm) & $173.8 \pm 4.3$ & $174.2 \pm 4.6$ & 0.528 \\
\hline Weight (kg) & $80.8 \pm 8.4$ & $73.4 \pm 7.7$ & $<0.001^{* * *}$ \\
\hline Body mass index $\left(\mathrm{kg} / \mathrm{m}^{2}\right)$ & $26.7 \pm 2.2$ & $24.1 \pm 2.1$ & $<0.001^{* * *}$ \\
\hline Body fat (\%) & $28.8 \pm 3.1$ & $21.0 \pm 3.0$ & $<0.001^{* * *}$ \\
\hline Muscle mass (kg) & $54.1 \pm 4.9$ & $54.5 \pm 5.7$ & 0.578 \\
\hline
\end{tabular}

Values are mean \pm standard deviation. ${ }^{* * *} p<0.001$; tested by independent $t$-test for each of the two groups at baseline. 


\subsection{Body Composition}

Body composition was measured using a bioelectrical impedance analysis device (InBody-270, Biospace, Seoul, Republic of Korea). For accurate measurements of body composition, alcohol intake was prohibited, and excessive physical activity or exercise was not allowed $24 \mathrm{~h}$ prior to the measurements being taken. Sufficient water intake was recommended to prevent dehydration. An empty stomach was maintained for the previous $8 \mathrm{~h}$, and hands were wiped using wet tissues before measurement.

\subsection{Physical Performance Test}

The physical performance tests included a 100-m sprint, push-ups, sit-ups, and a hand-grip strength test. Performance tests involving these four components are undertaken annually by current police officers under the direction of the Korean National Police Agency. All tests were based on the standardized fitness protocol used by the Korean National Police Agency. All tests were measured at the same location over 3 days, and participants assembled at 9 AM. A warm-up session including running and stretching was conducted before the tests were performed.

The 100-m sprint is a representative test for evaluating power. The test was conducted on a running track where the start line and finish line were well marked in white paint. The participants stood at the starting line and sprinted to the finish line while being timed. The time the participant crossed the finish line was used as the final record.

The push-up test evaluates muscular endurance. The participants continuously repeated push-ups by keeping their back straight while raising their body by pressing down on their hands, with both hands positioned according to the width of the shoulders and their feet together, such that the distance between the body and legs and the mat was within $5 \mathrm{~cm}$, and then returning to the original position. One push-up was only counted when this action was fully completed. Push-ups were measured for $1 \mathrm{~min}$, and only fully completed push-ups were used as the final record.

The sit-up test was used to evaluate muscular endurance. The participant lay supine on a mat, placed both feet approximately $30 \mathrm{~cm}$ apart, and bent the knees at a right angle, with both hands crossed in front of the chest. When the researcher gave a start signal, the participant raised his/her upper body, touched both elbows on both knees, and then returned to the original position. When both elbows did not accurately touch both knees, or when sit-ups were performed using rebound of the body, this was regarded as an error and was not counted. Sit-ups were counted for $1 \mathrm{~min}$, and only those completed correctly were used as the final record.

Finally, a hand-grip strength test evaluated muscle strength, and a dynamometer (TKK-5401, TAKEI, Niigata, Japan) was used for measurements. The participant held the dynamometer and gripped it with maximum possible force while holding the torso and arms straight. Participants were not permitted to shake their body or bend their arms during the measurement. Two measurements were taken for both the left and right hands, and the average of the four measurements was used as the final record.

\subsection{Statistical Analysis}

For statistical analysis, IBM SPSS Statistics ver. 21.0 (IBM Co., Armonk, NY, USA) was used. All study results are described using mean and standard deviation. Independent sample $t$-tests were performed to identify differences between groups in accordance with \%fat, and Pearson's correlation analysis was performed to investigate the correlation between \%fat and physical performance. The statistical significance level was set to 0.05 .

\section{Results}

Table 2 shows the differences between the HFG and LFG, classified according to the \%fat of the male Korean police officers participating in this study. Significant differences were detected between 
the HFG and LFG in the 100-m sprint $(p=0.001)$ and sit-up tests $(p=0.033)$. In the HFG, the 100-m sprint records showed significantly slower times than in the LFG, and the sit-up records showed completion less often. By contrast, no significant difference was found in push-ups $(p=0.130)$ or hand-grip strength $(p=0.255)$ between the groups.

Table 2. Differences in physical performance according to percentage body fat.

\begin{tabular}{|c|c|c|c|}
\hline Variable & Group & Mean \pm Standard Deviation & $p$ \\
\hline \multirow{2}{*}{ 100-m sprint (sec.) } & $\operatorname{HFG}(\mathrm{n}=135)$ & $16.4 \pm 1.8$ & \multirow{2}{*}{$0.001 * *$} \\
\hline & LFG $(n=191)$ & $15.7 \pm 1.8$ & \\
\hline \multirow{2}{*}{ Push-ups (reps/min) } & HFG $(n=135)$ & $37.9 \pm 5.2$ & \multirow{2}{*}{0.130} \\
\hline & LFG $(n=191)$ & $38.9 \pm 6.4$ & \\
\hline \multirow{2}{*}{ Sit-ups (reps/min) } & $\operatorname{HFG}(\mathrm{n}=135)$ & $44.1 \pm 6.0$ & \multirow{2}{*}{$0.033 *$} \\
\hline & $\operatorname{LFG}(\mathrm{n}=191)$ & $45.5 \pm 6.0$ & \\
\hline \multirow{2}{*}{ Hand-grip strength $(\mathrm{kg})$} & HFG $(n=135)$ & $53.9 \pm 6.2$ & \multirow{2}{*}{0.255} \\
\hline & LFG $(n=191)$ & $54.8 \pm 6.5$ & \\
\hline
\end{tabular}

HFG: high \%fat group ( $\geq 25 \%)$; LFG: low \%fat group $(<25 \%) .{ }^{*} p<0.05,{ }^{* *} p<0.01$; tested by independent $t$-test for each of the two groups.

Table 3 shows the correlation analysis between \%fat and physical performance. There was a significant positive correlation between the 100-m sprint and \%fat $(r=0.255, p<0.001)$ and a significant inverse correlation between push-ups and \%fat $(r=-0.117, p=0.035)$ and between sit-ups and \%fat $(r=-0.199, p<0.001)$. However, there was no significant correlation between \%fat and hand-grip strength $(r=-0.093, p=0.095)$.

Table 3. Correlations between percentage body fat and physical performance.

\begin{tabular}{ccc}
\hline Variable & \multicolumn{2}{c}{ \%Body Fat } \\
\cline { 2 - 3 } & $\mathbf{r}$ & $\boldsymbol{p}$ \\
\hline 100-m sprint (sec.) & 0.255 & $<0.001^{* * *}$ \\
\hline Push-ups (reps/min) & -0.117 & $0.035^{*}$ \\
\hline Sit-ups (reps/min) & -0.199 & $<0.001^{* * *}$ \\
\hline Hand-grip strength $(\mathrm{kg})$ & -0.093 & 0.095 \\
\hline${ }^{*} p<0.05,{ }^{* * *} p<0.001$; tested by Pearson's correlation analysis.
\end{tabular}

\section{Discussion}

We investigated the correlation between \%fat and physical performance, measured using a 100-m sprint, push-ups, sit-ups, and hand-grip strength in male Korean police officers. The results showed that high \%fat in male Korean police officers correlated to poor performance in the 100-m sprint, sit-ups, and push-ups, consistent with our hypothesis. These results were similar to those of several studies that reported that high \%fat in police officers can adversely affect their physical performance [10-12].

Police officers face various dangers. To be active and respond effectively in every situation, officers need to be able to move quickly, run, push, pull, and lift and carry heavy weights, as may be necessary. Moreover, they carry a bullet-proof vest, a communication system, weaponry, handcuffs, and personal protective equipment on their body when performing their duties [14-16]. For these reasons, police officers should maintain good physical performance throughout their careers. Nevertheless, the body composition of current police officers has been reported to be unhealthy [17]. Obesity continues to increase, and the level of \%fat has been found to be high within this population [10,18]. These results suggest that police officers who have not maintained good physical performance and who confront 
criminals or face certain risky situations may be less likely to effectively respond and may be more likely to be injured $[19,20]$.

Currently, in the required physical performance assessment of a Korean police officer, tests are undertaken such as running a certain distance quickly or repeatedly moving local muscle groups. If an officer's \%fat level is high, he/she may not be able to run sufficiently fast, and it may be more difficult to repeatedly perform the required tasks multiple times within a limited time in tests using one's own weight, such as with push-ups and sit-ups.

Police officers tend to take many shifts, resulting in irregular sleeping hours. Therefore, they tend to compensate for the lack of sleep [21] by sleeping more during their off-shift hours rather than being active, which may further reduce their opportunities to exercise. Furthermore, officers' work environments, in which they spend much time sitting in a patrol car driving or sitting in the office doing paperwork [22], has been found to adversely affect their physical performance and increase their \%fat levels. Nevertheless, there was no significant difference found in terms of hand-grip strength between the two groups. Some studies have reported that there was no significant correlation between $\%$ fat and hand-grip strength in normal weight or overweight participants $[23,24]$. This may be because hand-grip strength might correlate more with muscle mass than \%fat [25]. This study also showed no significant difference in terms of muscle mass between the two groups, although the two groups were similar in this regard [25].

Based on the results of this study, it is recommended that a training program be developed and applied to improve physical performance and reduce the \%fat of police officers. Several studies have suggested that police officers should be given the opportunity to exercise and be provided with regular training programs $[8,26]$. A randomized training program (RTP) or a periodized training program (PTG) is needed when considering various factors such as police officers' working environments and schedules. According to a study by Cocke et al., the \%fat level of police academy cadets reduced after undergoing two training programs, an RTP and a PTG, and their physical performance improved in terms of push-ups, sit-ups, and a 300-m sprint [27].

This study had some limitations. First, it is difficult to generalize the results of the study because the participants were limited to those working at Daegu Dongbu police station, in Daegu-si, Gyeongsangbuk-do, Republic of Korea. Future studies are needed involving greater numbers of study participants. Second, potential variables regarding departmental differences within the police organization, e.g., in-office vs. out-of-office positions, were not considered. In-office positions involve tasks similar to those of general corporate office workers, whereas frequent dispatch and walking patrols are included in out-of-office positions. Varying work responsibilities might affect police officers' body compositions differently. Third, only four tests used by the Korean National Police Agency were used in this study to measure physical performance. These tests can only determine power, muscle strength, and muscular endurance. However, recent studies have reported that aerobic fitness may be more important than power or strength for police officers in performing their duties [28] and that improving agility and aerobic fitness for better occupational performance should be focused on [29]. Tests involving agility and aerobic fitness should be included in future studies. Fourth, \%fat was the only index of body composition assessed in this study. In future studies, additional measures of body composition, e.g., abdominal obesity or muscle mass, measured using waist circumference measurements, and a waist-to-hip ratio would provide more diverse analyses. Finally, the cross-sectional design, which is an observational study design, is a major limitation. This study design does not provide evidence for a temporal relationship as it involves a one-time measurement of outcome after exposure. Thus, it is difficult to draw causal relationships without longitudinal data [30]. 


\section{Conclusions}

High \%fat in male Korean police officers correlated with reduced physical performance. Therefore, it is necessary to reduce \%fat and improve physical performance by applying an intervention program such as training. In future studies, it will be necessary to investigate changes in physical performance or health-related factors after applying a regular training program for male Korean police officers.

Author Contributions: Study design: J.K. and S.K. Study conduct: J.K., W.-Y.S., and S.K. Data collection: S.K. Data analysis: J.K. Data interpretation: J.K., W.-Y.S., and S.K. Drafting the manuscript: J.K., W.-Y.S., and S.K. Revising the manuscript content: J.K., W.-Y.S., and S.K. All authors have read and agreed to the published version of the manuscript.

Funding: This research received no external funding.

Conflicts of Interest: The authors declare no conflict of interest.

\section{References}

1. Hartley, T.A.; Burchfiel, C.M.; Fekedulegn, D.; Andrew, M.E.; Knox, S.S.; Violanti, J.M. Associations between police officer stress and the metabolic syndrome. Int. J. Emerg. Ment. Health 2011, 13, 243-256. [PubMed]

2. Maupin, D.; Robinson, J.; Wills, T.; Irving, S.; Schram, B.; Orr, R. Profiling the metabolic fitness of a special operations police unit. J. Occup. Health 2018, 60, 356-360. [CrossRef] [PubMed]

3. Vuković, M.; Kukić, F.; Čvorović, A.; Janković, D.; Prćić, I.; Dopsaj, M. Relations between frequency and volume of leisure-time physical activity and body composition in police officers. Res. Q. Exerc. Sport 2020, 91, 47-54. [CrossRef] [PubMed]

4. $\quad$ Chang, J.H.; Huang, P.T.; Lin, Y.K.; Lin, C.E.; Lin, C.M.; Shieh, Y.H.; Lin, Y.C. Association between sleep duration and sleep quality, and metabolic syndrome in Taiwanese police officers. Int. J. Occup. Med. Environ. Health 2015, 28, 1011-1023. [CrossRef]

5. Alghamdi, A.S.; Yahya, M.A.; Alshammari, G.M.; Osman, M.A. Prevalence of overweight and obesity among police officers in Riyadh City and risk factors for cardiovascular disease. Lipids Health Dis. 2017, 16, 79. [CrossRef]

6. da silva, f.c.; Hernandez, S.S.; Arancibia, B.A.; Castro, T.L.; Filho, P.J.; da Silva, R. Health-related quality of life and related factors of military police officers. Health Qual. Life Outcomes 2014, 12, 60. [CrossRef]

7. Vancini, R.L.; de Lira, C.A.; Anceschi, S.A.; Rosa, A.V.; Lima-Leopoldo, A.P.; Leopoldo, A.S.; Rufo-Tavares, W.; Andrade, M.S.; Nikolaidis, P.T.; Rosemann, T.; et al. Anxiety, depression symptoms, and physical activity levels of eutrophic and excess-weight Brazilian elite police officers: A preliminary study. Psychol. Res. Behav. Manag. 2018, 11, 589-595. [CrossRef]

8. Lagestad, P.; van den Tillaar, R. A comparison of training and physical performance of police students at the start and the end of three-year police education. J. Strength Cond. Res. 2014, 28, 1394-1400. [CrossRef]

9. Sörensen, L.; Smolander, J.; Louhevaara, V.; Korhonen, O.; Oja, P. Physical activity, fitness and body composition of Finnish police officers: A 15-year follow-up study. Occup. Med. 2000, 50, 3-10. [CrossRef]

10. Dawes, J.J.; Orr, R.M.; Siekaniec, C.L.; Vanderwoude, A.A.; Pope, R. Associations between anthropometric characteristics and physical performance in male law enforcement officers: A retrospective cohort study. Ann. Occup. Environ. Med. 2016, 28, 26. [CrossRef]

11. Violanti, J.M.; Ma, C.C.; Fekedulegn, D.; Andrew, M.E.; Gu, J.K.; Hartley, T.A.; Charles, L.E.; Burchfiel, C.M. Associations between body fat percentage and fitness among police officers: A statewide study. Saf. Health Work 2017, 8, 36-41. [CrossRef] [PubMed]

12. Dominski, F.H.; Crocetta, T.B.; Santo, L.B.D.E.; Cardoso, T.E.; da Silva, R.; Andrade, A. Police officers who are physically active and have low levels of body fat show better reaction time. J. Occup. Environ. Med. 2018, 60, 1-5. [CrossRef] [PubMed]

13. Paek, J.K.; Kim, J.; Kim, K.; Lee, S.Y. Usefulness of relative fat mass in estimating body adiposity in Korean adult population. Endocr. J. 2019, 66, 723-729. [CrossRef] [PubMed]

14. Bock, C.; Stierli, M.; Hinton, B.; Orr, R. The Functional Movement Screen as a predictor of police recruit occupational task performance. J. Bodyw. Mov. Ther. 2016, 20, 310-315. [CrossRef] [PubMed]

15. Bonneau, J.; Brown, J. Physical ability, fitness and police work. J. Clin. Forensic Med. 1995, 2, 157-164. [CrossRef] 
16. Tomes, C.; Orr, R.M.; Pope, R. The impact of body armor on physical performance of law enforcement personnel: A systematic review. Ann. Occup. Environ. Med. 2017, 29, 14. [CrossRef] [PubMed]

17. Alasagheirin, M.H.; Clark, M.K.; Ramey, S.L.; Grueskin, E.F. Body mass index misclassification of obesity among community police officers. AAOHN J. 2011, 59, 469-475. [CrossRef]

18. Zhang, J.; Liu, Q.; Long, S.; Guo, C.; Tan, H. Prevalence of metabolic syndrome and its risk factors among 10,348 police officers in a large city of China: A cross-sectional study. Medicine 2019, 98, 17306. [CrossRef]

19. Lentz, L.; Randall, J.R.; Guptill, C.A.; Gross, D.P.; Senthilselvan, A.; Voaklander, D. The association between fitness test scores and musculoskeletal injury in police officers. Int. J. Environ. Res. Public Health 2019, 16, 4667. [CrossRef]

20. Orr, R.; Pope, R.; Peterson, S.; Hinton, B.; Stierli, M. Leg power as an indicator of risk of injury or illness in police recruits. Int. J. Environ. Res. Public Health 2016, 13, 237. [CrossRef]

21. Garbarino, S.; Nobili, L.; Balestra, V.; Cordelli, A.; Ferrillo, F. Sleep disorders and day sleepiness in a population of shift workers of the State Police. G. Ital. Med. Lav. Ergon. 1999, 21, 13-19. [PubMed]

22. Violanti, J.M.; Fekedulegn, D.; Andrew, M.E.; Hartley, T.A.; Charles, L.E.; Miller, D.B.; Burchfiel, C.M. The impact of perceived intensity and frequency of police work occupational stressors on the cortisol awakening response (CAR): Findings from the BCOPS study. Psychoneuroendocrinology 2017, 75, 124-131. [CrossRef] [PubMed]

23. Lad, U.P.; Satyanarayana, P.; Shisode-Lad, S.; Siri, C.C.; Kumari, N.R. A Study on the correlation between the body mass index (BMI), the body fat percentage, the handgrip strength and the handgrip endurance in underweight, normal weight and overweight adolescents. J. Clin. Diagn. Res. 2013, 7, 51-54. [PubMed]

24. Ravisankar, P.; Ravisankar, P.; Madanmohan; Udupa, K.; Prakash, E.S. Correlation between body mass index and blood pressure indices, handgrip strength and handgrip endurance in underweight, normal weight and overweight adolescents. Indian J. Physiol. Pharmacol. 2005, 49, 455-461. [PubMed]

25. Shin, H.I.; Kim, D.K.; Seo, K.M.; Kang, S.H.; Lee, S.Y.; Son, S. Relation between respiratory muscle strength and skeletal muscle mass and hand grip strength in the healthy elderly. Ann. Rehabil. Med. 2017, 41, 686-692. [CrossRef] [PubMed]

26. Teixeira, J.; Monteiro, L.F.; Silvestre, R.; Beckert, J.; Massuça, L.M. Age-related influence on physical fitness and individual on-duty task performance of Portuguese male non-elite police officers. Biol. Sport 2019, 36, 163-170. [CrossRef] [PubMed]

27. Cocke, C.; Dawes, J.; Orr, R.M. The Use of 2 conditioning programs and the fitness characteristics of police academy cadets. J. Athl. Train. 2016, 51, 887-896. [CrossRef]

28. Robinson, J.; Roberts, A.; Irving, S.; Orr, R. Aerobic fitness is of greater importance than strength and power in the load carriage performance of specialist police. Int. J. Exerc. Sci. 2018, 11, 987-998. [PubMed]

29. Frio Marins, E.; Cabistany, L.; Bartel, C.; Dawes, J.J.; Boscolo Del Vecchio, F. Aerobic fitness, upper-body strength and agility predict performance on an occupational physical ability test among police officers while wearing personal protective equipment. J. Sports Med. Phys. Fitness 2019, 59, 1835-1844. [CrossRef] [PubMed]

30. Setia, M.S. Methodology Series Module 3: Cross-sectional Studies. Indian J. Dermatol. 2016, 61, $261-264$. [CrossRef] [PubMed]

(C) 2020 by the authors. Licensee MDPI, Basel, Switzerland. This article is an open access article distributed under the terms and conditions of the Creative Commons Attribution (CC BY) license (http://creativecommons.org/licenses/by/4.0/). 